\title{
El gobierno carcelario en la última dictadura argentina: la experiencia de las presas políticas (Villa Devoto, 1975-1981)
}

\author{
The prison government in the last Argentinean civil-military dictatorship: the \\ political women prisoners experience (Villa Devoto, 1975-1981)
}

\author{
Guillermina Laitano*
}

\begin{abstract}
Resumen: El objetivo del artículo es describir el régimen de gobierno carcelario implementado por el servicio penitenciario y las fuerzas armadas en la cárcel de Villa Devoto durante la última dictadura cívico-militar argentina. Se analizan las características que adquiere el gobierno de la cárcel cuando trata con una población específica, las presas políticas. La fuente empírica es la Colección Cartas de la Dictadura (Biblioteca Nacional), con lo cual el análisis parte de la propia experiencia y voz de las mujeres que allí se encontraban prisioneras.
\end{abstract}

Palabras clave: presas políticas; dictadura; cárcel; gobierno; cartas

\begin{abstract}
The objective of the paper is to describe the prison government system implemented by penitentiary service and the armed forces on Villa Devoto prison during the last Argentinean civil-military dictatorship. The characteristics acquired by prison government when dealing with a specific population, the political women prisoners, are analyzed. The empirical resource is the Dictatorship Letters Collection (National Library), thus the analysis start from the women prisoner own experience and voice.
\end{abstract}

Keywords: political women prisoners; dictatorship; prison; government; letters.

Recibido: 14 marzo 2017

Aceptado: 11 octubre 2017

\footnotetext{
* Argentina; licenciada en Sociología por la UNMdP (Universidad Nacional de Mar del Plata) y doctoranda en Historia por la UNCPB (Universidad Nacional del Centro de la Provincia de Buenos Aires); becaria doctoral del CONICET; Centro de Estudios Históricos, UNMdP; guillermina.laitano@yahoo.com
} 


\section{Introducción}

El presente trabajo ${ }^{1}$ propone una indagación exploratoria acerca de la prisión política "legal" durante la última dictadura cívico militar en Argentina ${ }^{2}$. Su objetivo es explorar y describir el régimen de gobierno carcelario implementado por el servicio penitenciario y las fuerzas armadas en la cárcel de Villa Devoto (Unidad $N^{\circ} 2$ del Servicio Penitenciario Federal) durante la última dictadura cívico-militar. Se trata de analizar las características particulares que adquiere el gobierno de la cárcel cuando trata con una población específica, en este caso las presas políticas. La fuente empírica del trabajo la constituye la colección "Cartas de la Dictadura", con lo cual el régimen de gobierno de la cárcel se analiza a partir de la propia experiencia y la propia voz de las presas políticas que allí se encontraban prisioneras.

En su carácter de exploratorio -y de unilateral en lo que refiere a las fuentes- el trabajo no pretende ni exhaustividad ni representatividad en relación a la forma que adquirió el gobierno carcelario cuando trató con presas políticas; se limita por el contrario a ser una exploración analítica del mismo, a partir de la correspondencia que las mujeres enviaron a sus familiares desde la cárcel. En este sentido, podemos decir que se trabaja fundamentalmente a partir de indicios ${ }^{4}$ que emergen en las cartas y que permiten desentrañar algunas parcialidades de la experiencia carcelaria por razones políticas.

Esta línea de análisis es fructífera en la medida en que habilita explorar analíticamente el régimen carcelario para presos políticos desde una nueva perspectiva: volver al pasado, al momento del encierro, no desde la memoria, sino desde documentos producidos durante ese preciso pasado y por sus propios protagonistas. Como señalan Jensen y Montero “(...) las cartas desvelan un universo de actitudes, comportamientos y experiencias de/en la cotidianeidad carcelaria, sin la mediación que imponen la situación de entrevista y la inevitable resignificación presente". 5

El régimen militar procuró ocultar y destruir toda documentación que diera cuenta del accionar represivo de los aparatos estatales de control social. ${ }^{6}$ En este sentido, nuestra

\footnotetext{
${ }^{1}$ Trabajo desarrollado en el marco de una beca de investigación otorgada por la Biblioteca Nacional a través del concurso “José Ingenieros” (2014).

2 Entrecomillamos la palabra legal para significar que la separación entre los aspectos "legales" e ilegales de la última dictadura es una falacia. La política represiva articuló cárceles y centros clandestinos de detención: efectuó la penetración de las fuerzas armadas al interior del servicio penitenciario; se asesinaron tanto secuestrados en centros clandestinos de detención como "detenidos legales" en cárceles; muchos militantes desaparecían en centros clandestinos y aparecían en cárceles y viceversa; la tortura fue una práctica instalada en ambos lugares así como también la clasificación de los detenidos en "recuperables" o "irrecuperables"; las familias tanto de presos como de secuestrados fueron hostigadas y aisladas. Calveiro, Pilar, "Prólogo", Garaño, Santiago y Werner Pertot Detenidos-aparecidos. Presas y presos políticos de Trelew a la dictadura, Buenos Aires, Biblos, 2007, p 17.

${ }^{3}$ Biblioteca Nacional de la República Argentina, Archivos y Colecciones Particulares.

${ }^{4}$ Ginzburg, Carlo, "Indicios. Raíces de un paradigma de inferencias indiciales", Mitos, emblemas, indicios. Morfología e historia, Barcelona, Gedisa, 2008, pp. 185-239.

5 Jensen, Silvina y María Montero, "La escritura epistolar como registro de la experiencia de encierro y represión en las cárceles argentinas (1974-1983)”, Historia Actual Online, n 31, primavera 2013, p. 147, disponible en http://historia-actual.org/Publicaciones/index.php/haol/article/view/849/709 (07/03/17).

${ }^{6}$ Ibid., pp. 143-157.
} 
fuente de análisis se transforma en un cúmulo de documentos que permiten sortear la estrategia del régimen de desinformación a la hora de reconstruir nuestro pasado reciente aportando al desarrollo de la memoria colectiva y a nuestro presente político.

En el primer apartado se presenta la fuente empírica y la estrategia metodológica de la investigación. Seguidamente se instala sucintamente el problema de investigación en su contexto histórico-social. Luego se presentan las características específicas de la cárcel de Villa Devoto, desde la cual fueron escritas las cartas. Finalmente se procede al análisis, el cual consiste en la reconstrucción del funcionamiento del gobierno carcelario cuando trata con un colectivo particular de presas: las políticas.

\section{Consideraciones metodológicas}

En la presente investigación asumimos una perspectiva de análisis micro, la cual permite pensar el proceso social objeto de estudio y las relaciones sociales de poder que lo conforman en un nivel capilar. Es un abordaje que "(...) se mueve en dimensiones sociales reducidas pero densas [y] nos permite reconstruir lo vivido y experienciado por las clases subalternas a ras del suelo, imposible de acceder desde una mirada macroanalítica". ${ }^{7}$

Trabajar desde una perspectiva micro nos permite tornar visible algunos aspectos del funcionamiento de la política de aniquilamiento de la última dictadura, allí donde disimuladamente opera: en la cotidianidad de un proceso social de castigo institucionalizado y legitimado socialmente- que emerge a la luz de las cartas que las presas políticas les escribieron a sus familias desde el encierro.

La correspondencia personal como fuente de análisis se caracteriza por albergar un contenido a partir del cual el investigador puede reconstruir aspectos de la vida social inaccesibles de otro modo, “(...) es un testimonio mudo que permanece físicamente, conserva su contenido a lo largo del tiempo y con él, sin embargo, se puede efectuar una entrevista. No se puede hablar directamente con él, pero puede ser interpretado". 8

La carta tiene la virtud de que nuestros "entrevistados" nos hablan hablándole a sus seres queridos, y entonces, con una confianza y una espontaneidad que habilita al investigador múltiples caminos de análisis que en otras circunstancias están negados. ${ }^{9}$

La colección "Cartas de la Dictadura"10 se compone fundamentalmente de cartas, si bien también incluye en un pequeño porcentaje cuentos y poesías, dibujos, escritos con reflexiones políticas y publicaciones de la época. Las cartas fueron producidas en los contextos del encierro carcelario y del exilio.

\footnotetext{
${ }^{7}$ Nieto, Agustín, "Los archivos policiales y la historia de las clases subalternas. El movimiento sindical marplatense a los ojos de la bonaerense", Los trabajadores del mar. Movimiento obrero en Mar del Plata (1957-1996), La Plata, Comisión Provincial por la Memoria (ex-DIPPBA), 2011, p. 3, cursivas en el original.

${ }^{8}$ Ruiz Olabuénaga, José Ignacio, Metodología de la investigación cualitativa, España, Universidad de Deusto, 2012, p. 193.

${ }^{9}$ da Silva Catela, Ludmila, "De eso no se habla. Cuestiones metodológicas sobre los límites y el silencio en entrevistas a familiares de desaparecidos políticos", Historia, Antropología y Fuentes Orales, n 24, 2000, pp. 69-75.

${ }^{10}$ El objetivo de la colección es recopilar material epistolar producido en el marco de la última dictadura cívico-militar (1976-1983). Sin embargo, tal delimitación cronológica no es tajante -pues el devenir histórico no lo es- y se encuentran en la colección cartas previas al golpe del 24 de marzo de 1976 así como también cartas producidas ya a partir del retorno a la democracia. Sus fechas extremas son 1974 y 1992.
} 
Al momento de realizar el relevamiento de los archivos (diciembre de 2014), había documentos de 16 donantes. De estas 16 donaciones, 9 corresponden a documentos producidos durante el exilio y 7 a documentos producidos desde el encierro carcelario -o hacia él. Nuestro trabajo de relevamiento consistió en fotografiar todo el material disponible $^{11}$, respetando el orden de conservación propio del archivo (el cual se basa en mantener el orden original dado a los documentos por los donantes así como su ordenamiento por donante).

Una vez fotografiado todo el material fue necesario organizarlo por carta (o poesía, cuento, etcétera) y por donante. Para ello elaboramos un código que permite rápidamente localizar los datos más relevantes de las cartas a la hora de seleccionarlas para su análisis. El código contempla las iniciales de los donantes, el número de carta, la situación de producción de la carta, el año de escritura, la legibilidad, el carácter de completa o incompleta, si fue sujeta a censura, y si fue destinada para -o escrita por- niños.

A partir de sistematizar el conjunto de cartas codificadas accedimos a un conocimiento más preciso del material de que disponemos, pudiendo seleccionar de esta manera aquellas cartas que se transformaron en la fuente empírica de la presente investigación, es decir, producidas en el contexto del encierro político.

En función de esta codificación y sistematización de la fuente se seleccionó para realizar un primer análisis aquellas cartas escritas desde la cárcel ${ }^{12}$ y destinadas a adultos. Se trata en total de cinco donantes y 442 cartas. Se elaboró una muestra de cada donante, la cual quedó conformada por 10 cartas de cada una, seleccionadas mediante la técnica de azar simple. Es decir que fueron seleccionadas para el análisis 50 cartas. Vale mencionar por último que las cinco donaciones sujetas a análisis son cartas escritas por mujeres. Todas pasaron por la cárcel de Villa Devoto muchos años (desde allí fueron escritas las cartas aquí analizadas) y una previamente pasó por el encierro en una Alcaidía de la ciudad de Rosario en la provincia de Santa $\mathrm{Fe}^{13}$. Las fechas extremas de las cartas seleccionadas son 1975 y 1981. Las citas introducidas en este trabajo se referencian indicando: una letra por donante (para referenciar cuando las citas corresponden a una misma identidad, pero manteniendo en el anonimato a las autoras); el número de carta según su orden original en la colección

\footnotetext{
${ }^{11}$ Con la excepción de tres donaciones que no pudieron ser fotografiadas por la falta de autorización de los donantes.

12 Dadas las características del archivo con el que trabajamos no nos es posible realizar un análisis que contemple la situación interaccional completa, es decir, tanto las cartas escritas desde la cárcel como sus respuestas, o sea, aquellas escritas hacia la cárcel. Tal situación hubiese permitido emprender un análisis que contemple al conjunto de cartas (desde y hacia la cárcel) de cada donante como un texto complejo pertinente de analizar en sí, lo cual habilitaría emerger otro camino analítico diferente al aquí abordado. Optamos en cambio -ateniéndonos a las características del archivo- por analizar las cartas en tanto conjunto analítico de textos singulares en función del cual derivar dimensiones analíticas transversales a las autoras de las cartas escritas desde la cárcel. Sobre la carta en tanto texto singular o parte de un texto complejo ver Castillo, Darcie Doll, "La carta privada como práctica discursiva. Algunos rasgos característicos", Revista Signos, 35 (51-52), 2002, pp. 33-57. Disponible en: http://www.scielo.cl/scielo.php?pid=S071809342002005100003\&script=sci_arttext, (03/02/15).

${ }^{13}$ En términos formales, una Alcaidía es una unidad penitenciaria - una cárcel- destinada al alojamiento de personas procesadas, esto es, personas que aún no han sido condenadas con sentencia firme. La fuente no nos permite conocer con exactitud cuánto tiempo estuvo allí la presa política antes de ser trasladada a la cárcel de Villa Devoto; sólo podemos consignar que hay cartas escritas por la autora desde Villa Devoto a partir del año 1976, sin embargo, hay que tener en cuenta que muchas de sus cartas carecen de fecha.
} 
"Cartas de la Dictadura"; y la fecha de escritura de la carta. De este modo, la carta número 20, escrita por E. en el año 1977, se indica: E. 20. 1977; mientras que la carta número 4, escrita por S. en la que no se consigna la fecha, se indica: S. 4. s/f.

Finalmente, durante el análisis de la fuente, se incorporó un nuevo material empírico producido a partir de un intercambio de correos electrónicos con una de las donantes. $^{14}$

\section{La prisión política en la última dictadura cívico-militar argentina}

Como ya han reseñado varios autores el estudio de los presos y las presas políticas durante la última dictadura cívico-militar en Argentina ha sido poco problematizado por los cientistas sociales. Muchos coinciden en que esta ausencia se debe en parte a que el foco de las investigaciones durante mucho tiempo se ha concentrado en el análisis de los procesos y aspectos más terribles, como la detención clandestina, la tortura, la desaparición de personas y el asesinato. ${ }^{15}$ No obstante, ya a partir de la década del 80 nos encontramos con una importante cantidad de trabajos testimoniales de los propios ex presos y presas políticas que comienzan a producir un relato de la propia experiencia vivida ${ }^{16}$; y en los últimos años, en el marco de una renovación desde el ámbito historiográfico sobre el campo temático relativo a la última dictadura comenzaron a emerger un conjunto importante de investigaciones que focalizan en el estudio de los presos y las presas políticas. ${ }^{17}$

Respecto de la dimensión cuantitativa de la prisión política, para el total de años de la última dictadura (1976-1983) se calcula que hubo un total aproximado de 10.000 presos políticos de los cuales 1.200 eran mujeres. ${ }^{18}$

Además, en consonancia con este crecimiento de detenidos políticos, sobre todo en la década previa al golpe del 76, el Servicio Penitenciario Federal experimentó fuertes cambios institucionales que redundaron en la conformación y ampliación de una infraestructura material estatal de control social -cárceles o partes de ellas-, bajo control de

\footnotetext{
${ }^{14}$ El intercambio se produjo entre el 27 de marzo y el 21 de abril de 2015 . Se trata de la donante Patricia Borensztejn, a quien agradezco especialmente, no sólo por la información brindada, sino porque a través de su prosa y poesía me acercó desde otra puerta al mundo de adentro, lo que habilitó otras miradas y otras sensibilidades.

${ }^{15}$ Seveso, César, "Escuelas de militancia: la experiencia de los presos políticos en Argentina, 1955-1972", $A$ Contra Corriente, vol. 6, $\mathrm{n}^{\circ}$ 3, 2009, pp. 137-165; Garaño, Santiago, Entre resistentes e "irrecuperables": Memorias de ex presas y presos políticos (1974-1983), Tesis de Licenciatura en Ciencias Antropológicas, Facultad de Filosofía y Letras, Universidad de Buenos Aires, 2008, disponible en http://www.antropojuridica.com.ar/wp-content/uploads/2012/03/GaranoTesis.pdf, (22/04/15); Guglielmucci, Ana, "Visibilidad e invisibilidad de la prisión política en Argentina: La 'cárcel vidriera' de Villa Devoto (1974-1983)", A Contra Corriente, vol. 4, n³, 2007, pp. 86-136.

${ }^{16}$ Seveso, op.cit.

17 Águila, Gabriela, "La dictadura militar argentina: interpretaciones, problemas, debates", Páginas. Revista Digital de la Escuela de Historia, UNR, año 1, n 1, 2008, pp. 11-27.

18 D’Antonio, Débora y Ariel Eidelman, "El sistema penitenciario y los presos políticos durante la configuración de una nueva estrategia represiva del Estado argentino (1966-1976)", Nueva Época, año 10, n 40, diciembre 2010, pp. 93-111.
} 
las Fuerzas Armadas, con agentes formados en una visión acorde a la Doctrina de Seguridad Nacional. ${ }^{19}$

En lo que refiere a los reglamentos penitenciarios destinados a los presos y las presas políticas se registra el reglamento aprobado el 26 de diciembre de 1974 por la presidenta María Estela Martínez de Perón mediante el decreto $2023^{20}$. Si bien este reglamento no presenta una normativa completamente diferente a los reglamentos vigentes para los presos comunes ${ }^{21}$ se observan diferencias cualitativas en algunas cuestiones. Entre ellas Garaño ${ }^{22}$ señala que a los presos políticos se les prohibía no simplemente cualquier "acto de indisciplina" como a los presos comunes, sino también particularmente cualesquiera "actividades políticas y/o gremiales"; se introducen/disponen las requisas; se reglamenta la posesión de material de lectura (sólo 3 libros y 2 revistas, previa autorización del servicio penitenciario); y se introducen cambios significativos en relación a la correspondencia. Ésta última para los presos comunes era "libre e inviolable", mientras que, en el caso de los presos políticos, el decreto 2023 establecía que la correspondencia quedaba sujeta a censura, examinación y posible retención por parte del servicio penitenciario, sólo habilitada para vínculos familiares directos comprobables, no permitida entre detenidos políticos más allá del lazo de familiaridad y debía guardar una estricta "corrección" de expresión -en idioma nacional.

Para el caso de las presas políticas de Villa Devoto, este reglamento entró en vigencia el 16 de junio de 1976, cuando el presidente de facto Jorge Rafael Videla ${ }^{23}$ lo hizo extensivo a todos los detenidos a disposición del PEN (Poder Ejecutivo Nacional) en cárceles de máxima seguridad -mientras que originariamente estaba previsto sólo para la cárcel de Rawson-. Asimismo, el 1 de julio de 1979 se aprobó un reglamento carcelario íntegramente elaborado por el poder dictatorial. Si bien guarda estrecha similitud con el reglamento del decreto 2023/74, introduce una diferencia sustancial: a los presos políticos ya no se los debe denominar "internos" sino "DT detenidos", es decir, "Detenidos Terroristas detenidos". ${ }^{24}$ Por lo que refiere a la correspondencia, a semejanzas del decreto 2023, el reglamento de 1979 "no ahorraba restricciones: no se podía hacer menciones al Servicio Penitenciario Federal o a autoridades nacionales, ni insultar; la misiva no podía contener ni recortes de diario ni revistas transcriptas, ni dibujos, ni croquis, ni fotografías, ni apuntes. Si la censura establecía que había un "agregado ambiguo o en caso de que se pretende dar una finalidad distinta a la misma", confiscaba la misiva". ${ }^{25}$ Junto a los reglamentos carcelarios, existieron además directivas militares secretas que gobernaron la

19 D'Antonio, Débora, “Género y resistencias en la prisión política durante la última dictadura”, Águila, Garaño y Scatizza (coord.), Represión estatal y violencia paraestatal en la historia reciente argentina, La Plata, UNLP, 2016, pp. 186-206; D’Antonio, 2010, op.cit.

${ }^{20}$ Vale señalar que el 6 de noviembre del mismo año la presidenta decretó el Estado de sitio.

${ }^{21}$ Reglamento para procesados de 1956 y Ley Penitenciaria Nacional de 1958 para condenados.

${ }^{22}$ Garaño, op.cit., pp. 80-84.

23 Integrante, junto con el almirante Emilio Massera y el brigadier Orlando Agosti, de la Junta de comandantes en Jefe de las Fuerzas Armadas, que el 24 de marzo de 1976 destituyó a la presidenta y nombró en su lugar al propio Videla.

${ }^{24}$ Garaño, op.cit.

${ }^{25}$ Pertot, Werner, "Palabras punibles. La ficción en la resistencia de los presos políticos", Iberoamérica, año $10, \mathrm{n}^{\circ} 40,2010$, p. 134. 
vida de los presos políticos. En el caso de la cárcel de Villa Devoto una de las directivas militares fue el "Plan de Conducta y Libertad". ${ }^{26}$

\section{La cárcel de Villa Devoto}

La Unidad $\mathrm{N}^{\circ} 2$ de mujeres del Servicio Penitenciario Federal, conocida como la cárcel de Villa Devoto, no fue una cárcel más, su ubicación geográfica le inscribió particularidades: estaba (y está) emplazada en un barrio de la Capital Federal. Esta situación le confirió una visibilidad y una "auditividad" que no tenía ninguna otra cárcel en el país, de modo que las presas políticas aquí encerradas accedieron a ciertas garantías sobre la vida inexistentes en otros lugares de represión. ${ }^{27}$

Es que, según las propias presas políticas, la cárcel de Villa Devoto funcionaba como una "cárcel vidriera", "como la cara visible de una estrategia represiva doble que incluía una fase de carácter ilegal." 28 . Los militares la utilizaban como "pantalla de la represión clandestina" ante los veedores internacionales, mientras que a las presas les permitía denunciar lo que sucedía al interior de la cárcel y la existencia de los centros clandestinos de detención, así como también ampliar los umbrales del grado de resistencia que se ejercía al interior de la cárcel. ${ }^{29}$

La cárcel se constituyó en un espacio de interacción de mujeres militantes de un modo muy diferente a lo vivido por los presos políticos varones. Pues, mientras todas las prisioneras fueron concentradas en la cárcel de Villa Devoto ${ }^{30}$, los hombres fueron sistemáticamente trasladados de cárcel en cárcel por diferentes provincias del país. ${ }^{31}$

\footnotetext{
26 "Este consistía en presionar de distintas maneras a las presas políticas para doblegarlas por medio de reducciones de derechos y de sanciones sistemáticas cumplidas en calabozo. (...) El objetivo del plan era inducir a las presas políticas a la firma de un acta pública de arrepentimiento para dominarlas políticamente." D'Antonio, Débora, "Reinterpretaciones, resistencias y negociaciones en la prisión política argentina 19741983", Outros Tempos, vol. 10, n. 16, 2013, p. 182.

${ }^{27}$ Ibid., pp. 182-184.

${ }^{28}$ Ibid., pp. 176; Beguán, Viviana (comp.), Nosotras, presas políticas, Buenos Aires, Nuestra América, 2006. La mayoría de las presas políticas que experimentaron la represión en la cárcel de Villa Devoto previamente al encierro allí, fueron ilegalmente detenidas y torturadas en Centros Clandestinos de Detención. D’Antonio, 2013, op.cit., p. 173; Guglielmucci, op. cit.

${ }^{29}$ D'Antonio, 2013, op. cit., p. 93; D’Antonio, 2016, op. cit. En este trabajo no nos focalizamos en el análisis de las resistencias que las presas políticas ejercieron en la cárcel de Villa Devoto. Presentamos una primera aproximación en Laitano, Guillermina, 2017, "La comunidad de las presas políticas: la producción de lazos de cooperación y de afectividad como prácticas políticas de resistencia", Actas de las XVI Jornadas Interescuelas, 9 al 11 de agosto, Mar del Plata. Análisis exhaustivos sobre las formas que adquirió la resistencia se encuentran en Guglielmucci, op. cit.; D’Antonio, 2013, op. cit.

${ }^{30}$ La concentración de las presas políticas en Villa Devoto comenzó en el año 1975 y culminó en 1979. Guglielmucci, op. cit.

${ }^{31}$ Idem. Para un análisis bajo una clave interpretativa de género del gobierno carcelario del penal de Rawson sobre los presos políticos allí prisioneros, ver D'Antonio, Débora, 'Los presos políticos del penal de Rawson: un tratamiento para la desubjetivación Argentina (1970-1980)”, Anos 90, Porto Alegre, v. 19, n. 35, 2012, p. 141-168.
} 
Villa Devoto fue una cárcel de máxima seguridad donde se segregó a las presas políticas, independientemente de la situación "legal" particular de cada una. Como reconstruye Garaño ${ }^{32}$, éstas podían ser detenidas a disposición de la justicia civil, de la justicia federal, de la justicia militar o del PEN. Si bien se trataba de una unidad penal perteneciente al Servicio Penitenciario Federal, el control de las presas definidas como "detenidas terroristas" lo ejercía el poder militar.

Los dispositivos disciplinarios que sufrieron las presas políticas -amén del maltrato físico directo- fueron la desinformación, la ignorancia de la presa acerca de su situación futura -inmediata- y de la de sus compañeras; la aislación entre ellas para evitar posibles estrategias colectivas; los traslados abruptos de pabellones o celdas (conocidos como la "calesita") para impedir y coartar los lazos afectivos entre las presas; la aplicación de sanciones que consistían en retiro de "beneficios", aislamiento en la propia celda o estadías en los calabozos de castigo ("chanchos"); la realización de las visitas sólo a través de un vidrio, de modo de impedir todo contacto físico con los familiares -incluyendo a sus hijos-; la censura de las cartas; alteraciones en el modo de ingreso y permanencia de libros y revistas; entre otros. ${ }^{33}$

Asimismo, de acuerdo al periodo del encierro hubo cambios en los reglamentos en cuanto a lo que estaba permitido o no hacer. Por ejemplo, en 1977 cuando se anunció el "Plan Conducta y Libertad" se prohibió el ingreso de material escrito, los papeles, lápices y lapiceras, la actividad física y manual y el préstamo de elementos entre presas; además se restringieron las horas de recreo y las visitas, se limitó la compra de artículos en la proveeduría del penal y se prohibió reír y cantar. ${ }^{34}$

Por otro lado, es necesario señalar que en tanto dispositivo disciplinario extra, todos los dispositivos mencionados no se aplicaban de modo sistemático como indicaban los reglamentos, sino con una discrecionalidad y selección que apuntaba a mantener siempre en la incertidumbre a las presas de lo que podía o no suceder en sus limitadas vidas diarias. No sólo por lo que indicaban los reglamentos, sino también por el ánimo del verdugo, cualquier acción u omisión podía convertirse en una excusa para castigar a las presas políticas. De este modo, la discrecionalidad en el funcionamiento de los dispositivos, aseguraba "el desconocimiento y la información básica para la orientación de las presas en el espaciotiempo carcelario". 35

Finalmente, hay que tener en cuenta que el contexto político e institucional varió considerablemente entre los años que se escribieron las cartas analizadas. ${ }^{36}$ Con lo cual,

\footnotetext{
${ }^{32}$ Garaño, op. cit.

${ }^{33}$ Guglielmucci, op. cit.; de Ípola, Emilio, La bemba. Acerca del rumor carcelario, Buenos Aires, Siglo XXI, 2005. Asimismo, Débora D’Antonio analiza la política de desubjetivación (de género y sexual) practicada por el poder carcelario-militar en Villa Devoto. Ver D'Antonio, Débora, "Políticas de desarticulación de la subjetividad sexual y de género practicadas en la cárcel de Villa Devoto durante la última dictadura militar argentina (1976-1983)", Estudios, n 25, 2011, 159-174.

${ }^{34}$ D'Antonio, 2013, op. cit.

${ }^{35}$ Guglielmucci, op. cit., p. 99

36 Por un lado está el periodo que comienza en noviembre de 1974 cuando la entonces presidenta constitucional decreta el Estado de sitio. A su vez, durante el golpe de estado (1976-1983) se pueden delimitar varios periodos también, no sólo en función de cambios que afectaron específicamente al interior de la cárcel (por ejemplo, la implementación del "Plan Conducta y Libertad" en 1977, o las diferentes visitas de veedores
} 
tanto las formas de gobierno del régimen carcelario, como las resistencias que a este opusieron las presas políticas, mutaron también. En el marco de un análisis exploratorio, en este trabajo se prioriza una descripción analítica de las formas de gobierno de carácter general y transversal a los diferentes periodos. Sin embargo, en los casos que la fuente nos lo permite, se indican las particularidades en función del contexto político.

\section{El régimen carcelario}

Así como en los documentos producidos desde el lugar del ejercicio del poder se pueden hallar indicios y reconstruir la historia de las clases subalternas, ${ }^{37}$ así también desde los documentos producidos por quienes sufren el ejercicio del poder se puede conocer algo acerca de su funcionamiento y de quiénes y cómo lo ejercen. Las cartas que las presas políticas de la dictadura escribieron a sus familiares, amén de la censura a que estaban sujetas, nos permiten reconstruir, a veces a partir de simples frases y pequeños señalamientos, cómo fue la vida de las presas políticas gobernada por el servicio penitenciario y las fuerzas armadas.

En términos generales, la vida de estas mujeres estaba sujeta -como en toda situación carcelaria- a una estricta disciplina. Todos los actos de la vida diaria estaban normados: con horarios, con posturas corporales, con prohibiciones, con regularidades.

En tanto institución de la época moderna, la cárcel le hace honores a la estricta medición del tiempo y al encuadramiento de la vida en función de él. Las presas políticas vivían bajo un régimen matemático de horarios. La mayoría de las acciones de la vida diaria estaban sujetas a reloj y todas eran anunciadas mediante un silbato. Desde la hora de levantarse: “... el pito del domingo es el mismo que el del lunes y martes y toda la semana a las 7 arriba, indiscutiblemente" (S. 16. s/f), hasta la hora de irse a dormir: "Bueno ya tocó el silbato, señal de que forzadamente me tengo que ir a hacer "noni'" (S. 46. s/f). Del mismo modo estaban normados los horarios de los recreos, tanto internos (dentro del pabellón) como externos (en el patio) -en las épocas y para los grupos de presas políticas en que estos existían-; el momento de reintegrarse a la celda; el momento de la comida: "serán las 17.30 hs y acaba de llegar la cena" (S. 35. s/f); y el momento en que la luz se apagaba -y por ende ya no se podía escribir más: “(...) ahora estoy escribiendo con el camisón ya puesto, debe faltar poquísimo para que apaguen la luz, y yo quiero enviar mañana esta carta si o si (...)" (P. 39. 1978).

Es interesante señalar la magnitud del impacto de la normatividad horaria en la vida de las presas políticas. Pensemos que estas mujeres estuvieron periodos prolongados de tiempo en esta situación de encierro (entre dos y diez años aproximadamente), es decir, que los horarios a que sus acciones estuvieron sujetas se repitieron no sólo día tras día, sino año tras año. En este sentido, un mínimo cambio en tal normatividad cobraba una especial significancia en la vida de estas mujeres en la medida en que rompía con la mecanización de la vida diaria: "(...) el jueves pasado llevaron a las chicas a misa y cuando volvieron, a eso de las 11 de la mañana nos llevaron al recreo externo. Fue lindo porque las 11 es el

internacionales), sino también en relación a un contexto nacional. Para este último caso ver Quiroga, Hugo, El tiempo del proceso. Conflictos y coincidencias entre políticos y militares, Rosario, Homo Sapiens, 2004.

${ }^{37}$ Ginzburg, Carlo, "El inquisidor como antropólogo", El hilo y las huellas. Lo verdadero, lo falso, lo ficticio, Buenos Aires, Fondo de Cultura Económica, 2011, pp. 395-411. 
horario de encierro de la mañana y fue la primera vez en muchísimo tiempo que salimos en ese horario" (P. 61. 1979). Definitivamente la luz del sol no es igual a las diez que a las once de la mañana, ni tampoco el calor que emana. Del mismo modo, los sonidos de los barrios, y las gentes que los habitan, también mutan de hora en hora (recordemos que el penal está ubicado en el barrio porteño de Villa Devoto).

Además, la normatividad horaria era fuertemente estricta como se deja ver en la siguiente cita, que relata cómo vivían las presas políticas el momento en que terminaba el recreo interno (de pabellón) y debían "reintegrarse" a sus celdas:

Y aquí, el carrito de la comida y el primer pito avisando el reintegro, corridas en los corredores, un libro que me olvidé de pasar a otra celda, la basura que no hay que olvidarse de tirar, el mate y la pava que estuvimos tomando en la celda de enfrente, y no te olvides de los fósforos que nos quedan sólo 3, corridas de una punta a la otra, la ropa seca del tendedero, y seguro que cuando suena el segundo pito no hicimos a tiempo para la mitad de las cosas, entonces hay que mirar por donde vienen cerrando, si de este lado o del de enfrente, uno siempre quiere quedarse afuera aunque sean unos minutos más. Ruidos de puertas, una detrás del [la] otra, y el barullo del pabellón se apaga como por arte de magia. Entonces quedamos solo 4. (P. 41. 1978)

El cuerpo también estaba sujeto a una disciplina estricta, tanto en lo que refiere a las posturas como al modo de vestirlo. Si bien no podemos señalar el momento exacto en que se uniformó -en términos de vestimenta- a las presas políticas, podemos señalar que fue entre marzo de 1976 y junio de 1977. Constó de un pantalón y una chaqueta azul: "en esta oportunidad te escribo en un lento atardecer, desde mi cama de arriba, rodeada de papeles de cartas viejas, proyectos de dibujos para los chicos y como corresponde de 'blue pinted of blue' con mi uniforme azul" (G. 134. 1979). Respecto de las posturas, las presas políticas tenían obligaciones que cumplir. Por ejemplo, cuando caminaban por fuera del pabellón debían ir con las manos atrás de la cintura y mirando hacia abajo. El siguiente testimonio muestra el abanico de consecuencias que podía implicar desobedecer esta norma: "Hoy tuve un pequeño problemita, salíamos al recreo y yo llevaba las manos atrás pero se me había desatado la campera y me la ato, cuestión que me quedo sin recreo y una hora y pico de plantón parada, pero luego felizmente volví a la celda con la idea de atarme firmemente los cordones de la campera en otra oportunidad, pero lo espero a [nombre del hijo] el martes y me llena de alegría que no pasó nada y podré verlo.” (G. 144. 1978). La cita permite observar que la falta podía dar lugar a tres tipos de castigo al menos. Primer castigo: quedarse sin el recreo externo; segundo castigo: el "plantón" (estar parada durante un tiempo prolongado de varias horas con las manos hacia atrás); tercer castigo: la "sanción disciplinaria", esto es, ser encerrada en las celdas de castigo por determinada cantidad de días y quedando privada de los recreos, de la correspondencia y de las visitas. Este tercer castigo era el que la presa política de la cita temía, puesto que su aplicación implicaba perder la oportunidad de ver a su hijo en la próxima visita. ${ }^{38}$

\footnotetext{
${ }^{38}$ Otras formas de aplicar la disciplina sobre los cuerpos, a partir de mediados de 1977, cuando se puso en
} marcha el "Plan Conducta y Libertad", fue la prohibición de realizar gimnasia, así como actividades 
La lógica carcelaria presenta cierta regularidad que las presas políticas van incorporando de a poco: los días y los horarios de las visitas de los hombres y de las mujeres, los días que pueden entregar cartas para mandar a sus familiares y los días que pueden recibirlas. Hasta las requisas en cierto momento se vuelven regulares para las presas políticas: "Resulta que el miércoles pasado, como lo teníamos previsto, vino la requisa (...)" (P. 31. 1977). Del mismo modo, con el correr del tiempo van habituándose a sus compañeras de celda, construyendo relaciones de amistad y solidaridad (tengamos en cuenta que las presas políticas pasaban la mayor parte del día encerradas de a cuatro en una celda); van construyendo modos de habitar los espacios; van acumulando objetos familiares, como cartas o fotos, manualidades construidas por ellas mismas; en fin, van permanentemente luchando por mantener y construir una identidad. Sin embargo, la cárcel en tanto institución esquizoide, y como mecanismo de gobierno, se caracteriza por desconcertar a sus prisioneros: todo lo que constituye para el sujeto una señal para ubicarse en la realidad particular que está viviendo puede, de golpe y sin previo aviso, mutar. Es el caso de los traslados de pabellón al interior del penal, dispositivo disciplinario muy común en las cárceles de la dictadura, conocido como "la calesita". 39

Queridos mamá y papá: Bueno hoy empiezo esta carta y con ella inauguro un nuevo periodo, o sea una nueva celda, nuevas vecinas, nuevas caras y una nueva ubicación, esta vez del lado del sol, y un poco más arriba, (...), pero bueno, ya estoy acomodada, instalada con todos mis pequeños grandes bártulos, y muchas cosas que dejé, algunas olvidadas con el apuro, otras a propósito, cosa de que queden pedacitos de mi presencia aunque ya no esté, muchos recuerdos lindos que guardo (...) se dan cuenta que este es un mundo, sólo que no tiene aeropuertos ni aviones, y además lo que es peor uno no compra el pasaje ni decide la fecha del viaje, todo es un imprevisto (...) un amarrón rápido, suficiente como para no dejarte pensar (...) (P. 71. 1980)

De acuerdo con los relatos de las cartas sufrir la "calesita" implicaba consecuencias afectivas y emocionales y de condiciones de vida diarias. Por un lado, dejar no sólo de convivir, sino también de ver, a las compañeras tanto de celda como de pabellón; por otro lado, enfrentarse a personas nuevas, no conocidas con anterioridad, con las cuales se empieza a convivir en la nueva celda. Además, los traslados conllevan el peligro de no poder llevarse al nuevo "hogar" las pertenencias, lo cual no es algo menor porque significa

manuales. Sin embargo, las presas políticas utilizando su creatividad sortearon estas prohibiciones. Ver Laitano, 2017, op. cit.; D’Antonio, 2013, op. cit.; Guglielmucci, op. cit., p. 115.

39 Teniendo en cuenta lo señalado en otras investigaciones, este dispositivo no entró inmediatamente en vigencia en tanto forma de gobierno de las presas políticas. Puesto que en el periodo previo al golpe y hasta la implementación del "Plan Conducta y Libertad" -mediados de 1977-, las presas políticas podían peticionar ante las autoridades del penal un cambio de celda o pabellón. Mediante estas peticiones, las presas organizaban su propia distribución en los pabellones en función de su filiación política. Una vez introducido el "Plan Conducta y Libertad", la ubicación de las presas en el penal dependió de la clasificación que se hiciera de ellas en tres grupos (G1, G2 y G3) en función de su "nivel de peligrosidad"; no obstante, las presas políticas opusieron aquí también sus formas de resistencia. En el caso particular de la "calesita", las presas políticas la utilizaron para la circulación de información y para el reconocimiento de los distintos espacios del penal. Ver Guglielmucci, op. cit., p. 110; Garaño, op. cit., p. 14-15; D’Antonio, 2013, op. cit., p. 182-185. 
perder ropa, cartas, fotos y múltiples objetos necesarios para la vida diaria en el mundo de la carencia ${ }^{40}$.

En este sentido, si bien existía cierta regularidad en la vida carcelaria, esta era precaria. Como señalan de Ípola y Guglielmucci ${ }^{41}$, la desinformación y la ignorancia acerca del futuro inmediato se constituyeron en dispositivos para el gobierno de la cárcel política. Y los cambios, siempre repentinos, impactaban directamente en las cuestiones más importantes para las presas políticas, como las visitas. Un cambio en la regularidad de la vida carcelaria, por ejemplo ser sancionadas o que se produjeran alteraciones en los días u horarios de las visitas, significaba dejar nulo el encuentro, perder el único momento semanal en que las presas políticas, a través de una reja o un vidrio, podían ver a sus familiares $^{42}$.

Por otro lado, la desinformación a que estaban sujetas las presas en tanto dispositivo disciplinario se completa como tal con su contraparte, el saber, que en Villa Devoto estaba en posesión del personal penitenciario. Como señala Guglielmucci" "La cárcel política llevó al extremo los mecanismos que aseguraran una distancia máxima entre el saber de las autoridades y la ignorancia de las detenidas". Sin embargo este dispositivo evidenció sus grietas en las prácticas de comunicación que erigieron las presas políticas como las cartas codificadas, el "caramelo" y el "canuto", entre otros ${ }^{44}$.

Las condiciones materiales en que vivían las presas políticas, como en todo espacio y tiempo carcelario argentino, eran deteriorantes. No podemos establecer con exactitud el lugar que la cárcel de Villa Devoto ocupaba en relación a las demás en este aspecto, pero como ya mencionamos, se trata de una cárcel particular: la cárcel "vidriera". Esta situación generaba ciertos "beneficios" que en otras cárceles o eran más precarios o directamente no existían, tal como se observa en la siguiente cita de una presa política que previamente al encierro en la cárcel de Villa Devoto estuvo detenida en una Alcaidía de la ciudad de Rosario: "Hoy con las chicas comparábamos esos meses pasados en Rosario: (...) sin cartas, sin visita, sin recreo, sin nada. Aquí tenemos todo eso y encima la comida nos reserva alguna sorpresa de vez en cuando (...). Por lo menos una vez por semana hay alguna novedad." (E. 20. 1977).

Por lo que refiere a las condiciones de vida de la cárcel de Villa Devoto, por un lado, hay que tener en cuenta las condiciones edilicias. En las cartas sobresale el

\footnotetext{
${ }^{40}$ La cuestión de la carencia que vivían las presas políticas en su vida diaria se revela a través de los incontables pedidos que en las cartas les hacen a sus familiares: elementos de limpieza (detergente, rejilla) y de aseo personal (jabón, champú, algodón, papel higiénico, cepillo de dientes, peine), ropa, papel, sobres y estampillas, lapiceras, toallas, repasadores, agujas e hilos, objetos para cocinar y comer, mates, sábanas, invisibles, tarros, libros, postales, fotos familiares. La cuestión de la carencia y los pedidos hechos a los familiares en las cartas fueron señaladas asimismo en D’Antonio, 2013, op. cit., p. 188.

${ }^{41}$ de Ípola, op. cit.; Guglielmucci, op. cit.

${ }^{42}$ Las visitas con reja de por medio se permitieron hasta mediados de 1977, cuando se construyeron los locutorios. El locutorio separaba a la presa de sus familiares mediante un vidrio, lo que impedía todo contacto físico entre ellos, incluso con sus hijos. Señala Débora D'Antonio que recién en diciembre de 1979, “tras largas disputas con el poder penitenciario (...) las mujeres pudieron reunirse con sus hijos e hijas en una visita de contacto de apenas quince minutos cada quince días". D'Antonio, 2011, op. cit., p. 170.

${ }^{43}$ Guglielmucci, op. cit., p. 99

${ }^{44}$ Para una descripción de las formas que adquirió la resistencia de las presas políticas en el caso de las formas de comunicación que desplegaron ver Guglielmucci, op. cit., p 99-103.
} 
sufrimiento de las temperaturas, que eran extremas. En invierno, durante el día usaban "dos o tres pulóveres", si llovía las goteras en los techos no se hacían esperar, la ducha era de agua fría y "no tienen lluvia, o sea sale un chorro, que en invierno te perfora los huesos" (S. 35. s/f); en el mes de diciembre todavía se dormía con frazada y "No les miento, pero el viento me despeina a la noche y no quiero pensar lo que será el invierno" (E. 20. 1977). Otras investigaciones ${ }^{45}$ han señalado la presencia de chinches, cucarachas y ratas en las celdas.

Por otro lado, las condiciones alimenticias eran pésimas, a punto tal que "se podía encontrar [comida] en estado de descomposición"46. Las presas políticas ponían en juego todos los recursos culinarios aprendidos en cada una de sus casas, e intentaban transformar la comida del penal, junto con los comestibles que compraban en la "proveeduría"47, en platos con gusto, y administrando un mínimo aporte de vitaminas y proteínas diario para cuidar la salud:

Bueno ya almorzamos un escalope con lechuga, no puedo decir ensalada porque fue solo eso: lechuga, con agua y cualquier cosa, menos lo normal en una ensalada. (...) el postre que nos han traído es arroz con leche, que es insípido, incoloro e inodoro, tres o cuatro arroces flotando en la leche aguada, 'cruda descripción del postre' pero real (S. 16. s/f)

Ya paso la merienda. Nos trajeron un pedazo de dulce de batata bastante chico y estuve como 3 hs para repartirlo en 21 pedacitos iguales, salió como una fetita, superfina y transparente (S. 35. s/f)

En la "proveeduría" no podía comprarse cualquier cosa ni de cualquier forma. No vendían estampillas, bien por demás preciado para las presas políticas. Tampoco podían comprar en ciertas cantidades (de un producto y de tipo de productos): "por supuesto que a mí con un kilo de queso fresco y frutas me alcanza y me sobra. Compro otras cosas porque no puedo comprar todo en dos productos solos" (G. 104. 1981). Además la lista de lo que estaban autorizadas a comprar variaba de tiempo en tiempo, en función del contexto político. $^{48} \mathrm{La}$ existencia de unas condiciones alimenticias pésimas, sumada a las limitaciones de los alimentos que les permitían ingresar a sus familiares o comprar en la "proveeduría", pueden interpretarse como forma de gobierno de las presas políticas que garantizaba el objetivo de anularlas política y subjetivamente. En la medida en que produjeron el deterioro físico de las presas políticas "(la mayoría de las mujeres bajó de peso un promedio de 10-15 Kg)" "49, produjeron también, a través de éste, el deterioro moral, político y subjetivo.

\footnotetext{
${ }^{45}$ Guglielmucci, op. cit.

46 Ibid., p. 113

47 De acuerdo a lo que hemos podido reconstruir, las mujeres llamaban "proveeduría" a un sistema que consistía en que una vez por semana la guardia retiraba los pedidos que hacía todo el pabellón, y a los dos o tres días lo traía. Básicamente las cosas que compraban las presas políticas eran: kerosene, azúcar, yerba, cigarrillos, harina y café. Sin embargo, la lista de lo que les autorizaban a comprar no siempre era igual, mutaba en sus gradientes de restricción.

48 Por ejemplo, cuando se implementó en 1977 el "Plan Conducta y Libertad", se limitó la lista de los productos que se podían comprar en la “proveeduría”. Ver D'Antonio, 2013, op.cit.

${ }^{49}$ Guglielmucci, op. cit., p. 126
} 
Retomando la situación de "cárcel vidriera" de Villa Devoto es interesante detenerse a observar aquella función que ésta cumplía cuando comenzaron a realizarse visitas por parte de veedores internacionales, una vez que las denuncias sobre violación de derechos humanos y prácticas de desaparición y asesinato sistemático de personas comenzaron a circular en el ámbito internacional. ${ }^{50}$ Ya mencionamos que la cárcel de Villa Devoto funcionó como "pantalla de la represión" 51 . Consistía en recibir allí a los veedores y "mostrarles" lo humanitario que era el régimen carcelario, mostraban presas "legales", mostraban condiciones edilicias decentes, mostraban alimentación saludable: "Ayer les cuento que vino por acá la Comisión de la OEA, pero yo no los vi porque este piso no lo recorrieron, avisaron a algunas chicas que se preparen, pero no las vieron. Lo que sí, comimos re bien, al mediodía, un pedazo inmenso de pollo con ensalada y queso con dulce de postre. Así que fue un día bastante especial, por cierto." (P. 61. 1979).

Otro aspecto relativo a las prácticas de gobierno penitenciario de la dictadura refiere a la correspondencia. Si bien el reglamento carcelario para detenidos a disposición del PEN que normaba lo relativo a la correspondencia había sido decretado por María Estela Martínez de Perón en 1974 (decreto 2023), según lo que emerge en las cartas ciertos artículos recién empezaron a aplicarse estrictamente luego del golpe de estado de 1976, como por ejemplo los relativos a la censura y a los destinatarios permitidos, como se observa en esta carta del 24 de junio de 1976: "Hace unos días nos comunican una nueva: [ilegible] escribirnos nada más que con familiares. Tuve que anotar con quien lo hacía (...). Ah! Otra de las disposiciones del penal, respecto a las cartas, es que las debemos entregar abiertas, ya que pasan por las manos de un censor seguramente, claro que ahora en forma legal" (S. 6. 1976).

Respecto de los destinatarios permitidos, las presas políticas y sus familiares debían comprobar -mediante copia del certificado de nacimiento- el vínculo familiar para poder mantener la correspondencia: "Sólo puedo escribir a los que anoté en la tarjeta de visita y sólo una carta hasta que demuestre el parentesco." (E. 20. 1977). En este sentido, en algunas cartas aparece en el margen superior izquierdo la señalización de dicho vínculo: "Carta para [nombre y apellido]. Vínculo comprobado = Hermana." (S. 24. s/f).

Respecto de la censura de las cartas, como señala el artículo 167 del decreto 2023/74, éstas podían ser abiertas, examinadas y retenidas por el servicio penitenciario. De las cincuenta cartas aquí analizadas veintitrés están marcadas con el sello de censura ${ }^{52}$, lo

\footnotetext{
50 Los organismos que actuaron como veedores internacionales fueron la Comisión Interamericana de Derechos Humanos (CIDH) de la Organización de Estados Americanos (OEA), el Comité Internacional de Cruz Roja (CICR) y Amnistía Internacional. La CIDH realizó una visita en 1979, y en 1980 redactó un informe respecto de la situación de los derechos humanos en Argentina. El CICR realizó visitas anuales a unidades penitenciarias federales a partir de 1977. Amnistía Internacional ingresó a la cárcel de Villa Devoto en noviembre de 1976. Si bien el objetivo del gobierno militar al permitir estas visitas fue cuidar la propia imagen de las fuerzas armadas ante el público internacional, éste no fue alcanzado en la medida en que los veedores internacionales legitimaron las denuncias de los organismos de Derechos Humanos y las denuncias que las propias presas políticas les comunicaron en las visitas. Guglielmucci, op. cit. p. 94-95; D’Antonio, 2013, op. cit. p. 185.

${ }^{51}$ En este sentido es que se ha definido a las presas políticas de Villa Devoto como "rehenes". Ver D'Antonio, Débora, 2011, op. cit., p. 162-164.

52 Los años de las cartas con el sello de censura van de 1976 a 1979, sin embargo, hay que tener en cuenta que muchas de las cartas censuradas oficialmente no contienen la fecha.
} 
cual significaba que la carta había sido revisada y que "su contenido no había infringido ninguna de las normas del censor". Puesto que cuando sí lo hacía, la carta directamente no salía del penal: “(...) escribime aquella carta que no dejaron pasar si tenés tiempo" (C. 81. 1978). Por eso, en palabras de una ex presa política "nuestras cartas eran muy vagas. Nos referíamos muy poco a lo que pasaba adentro". 53

Respecto de la censura, el penitenciario que cumplía esta función -según recuerda la ex presa política entrevistada- era el "maestro", llamado así porque era quien se encargaba, además de la censura de las cartas, de recibir -y autorizar o no- los libros que las familias les mandaban a las presas políticas. Interpretamos que su nivel educativo era más bien bajo por las contradicciones entre sus acciones y las directivas del régimen. Estas contradicciones se perciben en algunas frases de las cartas y en algunos de los libros que "pasaban" la censura y llegaban a las presas políticas. En efecto, como nos señaló nuestra entrevistada, muchas veces el criterio que el "maestro" utilizaba para examinar un libro era simplemente el título, y de este modo de acuerdo a la "inocencia" o no de los títulos los libros entraban o no. Este es el caso de la novela Resurrección de León Tolstoi, que no sólo fue leída en la cárcel de Villa Devoto de la dictadura, sino también comentada en una carta con total franqueza:

Siguiendo en el encierro, hemos leído el libro "Resurrección" de Tolstoi, nos gustó mucho. Habla del principio al fin de las cárceles de Rusia de $188 . .$. a través de un príncipe que, viendo esa realidad y la pobreza general, las injusticias judiciales que le toca vivir de cerca, decide abandonar su modo de vida, pero no sabe bien que hacer, ni se decide del todo a entregar por ejemplo sus tierras a los campesinos. Al final lo hace, pero sigue sin encontrar respuesta a las preguntas que se hacía a partir de lo que veía. ¿Por qué unos castigan a otros? ¿Por qué muchas veces los castigados son inocentes? ¿Quién les ha dado el poder de juzgar a quienes lo hacen y muchas veces (la mayoría) a inocentes? Todo el libro tardó para llegar a una respuesta que lo convenciera a él. Leyó, entró a cárceles a observar, con permisos especiales pues tenía influencia (era príncipe muy conocido), habló con militares, etc. Llegó a la conclusión de que todo estaba corrupto de igual forma, que los que juzgaban corrompían a los juzgados que a su vez corrompían a los inocentes que estaban a su lado y así era un círculo. Los primeros eran así, crueles por el puesto que les había tocado ocupar en la vida y los segundos eran llevados a eso por la miseria (ladrones, asesinos, presos políticos) (...) (C. 61. 1979)

En concordancia con los hallazgos de otras investigaciones sobre la temática ${ }^{54}$, esta cita nos permite observar que la cárcel de la dictadura poseía grietas. Grietas por donde se filtraban acciones que estaban prohibidas para las presas políticas: la comunicación, la reflexión, el pensamiento crítico.

Por otro lado, de acuerdo al contexto político e institucional, la correspondencia no llegaba siempre en tiempo y forma. A veces estaban un tiempo largo sin recibirla y de

53 Cita de una conversación mantenida vía correo electrónico el 27 de marzo de 2015 con Patricia Borensztejn, una de las presas políticas cuyas cartas donadas son aquí objeto de análisis.

${ }^{54}$ Guglielmucci, op. cit.; D’Antonio, 2013, op. cit. 
golpe entregaban varias cartas juntas: "esta semana recibí un aluvión de cartas de ustedes, las de los domingos de papá con los giros, una de mamá y otra de [nombre], también recibí las postales y ayer me entregaron la foto. (...) la voy a poner junto con las otras dos (...) y ya me pueden mandar alguna otra porque llegan bien" (P. 29. 1977).

Una de las prácticas que asume el gobierno de la población presa, política o no, es la requisa: revisión y control total de los cuerpos, las pertenencias y los espacios. Si bien formalmente es una práctica que permite a los servicios penitenciarios inspeccionar y controlar la posible existencia de objetos prohibidos en la cárcel, en la práctica se transforma en un momento de ejercicio del poder que habilita tratos crueles, golpes y vejámenes $^{55}$. Por supuesto que este tipo de prácticas no van a emerger en las cartas analizadas, sin embargo, a través de ellas podemos, en tanto primera aproximación al tema, explorar cómo era vivida la requisa por las presas políticas en función de lo que les trasmitían a sus familiares de esta situación. Por un lado en las cartas surge el hecho de que en las requisas el servicio penitenciario "confiscaba" pertenencias de las presas políticas como cartas, libros y estampillas ${ }^{56}$. Por otro lado, las descripciones de las cartas nos permiten dimensionar el avasallamiento sobre la vida que implicaba esta práctica penitenciaria:

Ahora es la siesta del martes y San Pedro nos jugó una mala pasada, pues llueve, no salimos al patio (...). A cambio vino a la mañana la requisa. Estuvimos como siempre alrededor de dos horas paradas en el lavadero mirando la pared y manos atrás. Luego hasta el mediodía (1 y 1/2) acomodando todo que esta vez estaba sumamente revuelto, y limpiamos, comimos (...) Luego me lavé un poco, también la cabeza mientras se calentaba la pava para los mates que ahora tomamos mientras escribimos o leemos. Es confortable ver todo limpio y uno también después del revoltijo (C. 11. 1980).

Todas las cárceles, sin distinción de épocas y regiones, se gobiernan a través de una lógica punitiva. Esto implica que todas las acciones están normadas y para cada trasgresión existe una sanción, un castigo. Claro que hay castigos legales, formalizados, definidos y reglados en decretos y reglamentos, y castigos ilegales, generalmente perpetrados en el marco de los primeros. En la cárcel de la dictadura, de acuerdo a nuestra fuente -que por supuesto no nos permite indagar los castigos ilegales-, encontramos la existencia de tres tipos de castigos "legales". El "plantón", la "restricción" (total o parcial) y la sanción en los calabozos de castigo (los "chanchos"). Respecto del "plantón" ya vimos que constaba en

\footnotetext{
${ }^{55}$ A su vez, en la práctica también se transforma en uno de los momentos donde "las manos invisibles" (los agentes penitenciarios) organizan el mercado económico ilegal que allí funciona. Ver Laitano, Guillermina y Agustín Nieto, 2017, "El castigo como relación social cotidiana en la Argentina actual. El caso de la cárcel de mujeres de Batán”, Revista Estudios Sociológicos, n 104, Colegio de México, pp. 293-318.

${ }^{56}$ Contar con estampillas (enviadas a través de los familiares o compradas en la "proveeduría" en algunos períodos) era fundamental para las presas políticas, puesto que las necesitaban para poder enviar cartas a sus familias. Así como el servicio podía confiscárselas en las requisas, las presas también elaboraban estrategias para conservarlas: "Las estampillas que me mandaste me las sacaron. (...) En las próximas mandame un sobre grande y adentro sobre con las estampillas pegadas y papel [ilegible] para escribir, porque el block este nos sale muy caro" (S. 4. s/f).
} 
dejar a la presa política parada con las manos atrás durante horas: “(...) 10 chicas estuvieron de "plantón" desde las 11 de la mañana hasta las 19. Cosa bastante usual en estos últimos tiempos, te acordás que un día te conté que estuve de esa forma, parada con manos atrás, no sé cuántas horas." (S. 14. s/f).

Por su parte la sanción de "restricción" implicaba la pérdida total o parcial de "beneficios" como recreos, internos y externos, correspondencia ${ }^{57}$, visitas, diarios y encomiendas. Cuando la restricción abarcaba los recreos se la llamaba "engome". Básicamente significaba estar encerradas en la celda durante días enteros (desde cinco días hasta un mes y medio, según nuestra fuente). Los motivos, o sea, las "faltas" adjudicadas en este tipo de sanciones, van desde cantar y hablar fuerte, pasando por rechazar la comida, hasta por el comportamiento asumido durante las requisas. En estas situaciones de encierro extremo, el tiempo se ocupaba en leer, cocinar, arreglar la ropa, elaborar manualidades, escribir cartas -cuando no estaba restringido también-, realizar cursos de alfabetización, talleres de historia y de política, entre otras. ${ }^{58} \mathrm{El}$ siguiente relato ejemplifica cómo las presas políticas vivían estos castigos:

Ya pasaron los 10 días [de sanción], estoy bien, hoy la celadora leyó al pabellón el parte de sanción que dice por proferir gritos en la requisa y ser indiferentes a los reiterados llamados de atención de la jefa de turno de requisa. Hubo requisa el lunes y la sanción comenzó el miércoles. Hoy ya es domingo, segundo día de "libertad" en el pasillo. Te imaginarás estamos contentas de volvernos a ver y poder charlar todas después de 10 días de ver las "figuritas repetidas" de la celda de la mañana a la noche (...) salimos a la mañana temprano [al recreo externo], serían 9 o $91 / 2$, estaba maravilloso. Algo que te resultará gráfico, después de muchos días sin recreo, cuando ponés el primer pie en el patio tenés que abrir los ojos de a poco porque la luz te encandila. El encierro se pasó como todos los encierros, sin harina esta vez, pero con un café con leche de merienda generalmente y algo de chocolate. Empiezo por la comida porque es muy importante como sabrás (...) estamos haciendo un librero de tela colgado de la pared para poner los libros, blocks para cartas, papelerío. (C. 61. 1979)..$^{59}$

Por último, está la sanción en los calabozos de castigo. Se los denominaba "chanchos" y tal denominación tenía que ver con las condiciones de higiene del lugar. Su tamaño aproximado era de 1,5 por 2 metros cuadrados, no contaban con letrina ni cama y se entregaba un colchón sólo desde las 10 de la noche hasta las 6 de la mañana siguiente. Era un lugar "pelado", lo único que había en ese espacio era una plancha de hierro amurada a la pared y que tenía agujeritos, exactamente "1440, distribuidos en veinticuatro filas de

\footnotetext{
${ }^{57}$ Cuando la restricción abarcaba la correspondencia, autorizaban a las presas -algunas veces- a enviar una nota a sus familiares avisando de la sanción, como se ve en esta carta que se cita completa, y que sólo contiene la fecha y dos palabras -además del sello de censura-: "28 de febrero de 1979. Estoy sancionada".

${ }^{58}$ Hay que tener en cuenta que muchas de las prácticas que las mujeres desarrollaban en el marco de las sanciones eran formas de resistencia directa en la medida en que, con gradientes según el contexto político e institucional, estaban prohibidas.

${ }^{59}$ En el relato se observa otra forma que adquirió la resistencia en la cárcel de Villa Devoto: no acatar las órdenes en el marco de las requisas.
} 
sesenta agujeritos cada una". ${ }^{60}$ Ir al baño dependía de la voluntad de la celadora. Las mujeres sancionadas en los "chanchos" quedaban totalmente incomunicadas. ${ }^{61}$ Una ex presa política testimonia: "Casi no hay luz, sólo los sueños te pueden salvar de la desesperación". ${ }^{62}$ La siguiente cita expresa de algún modo el extremo de aislamiento -un encierro dentro de otro encierro- a que se sometía a las mujeres en estas situaciones, al punto tal que:

Cuando estaba en esa celdita en los chanchos extrañaba mi celda del tercer piso, el calor del calentador, el olor a las tostadas, la charla con mis compañeras. Y después pensaba, pero que absurdo desear volver a una celda que al fin y al cabo tendrá más comodidades pero que no por eso deja de ser una celda, donde estoy tan encerrada como en cualquier otro lado (P. 29. 1977).

Por otro lado, la aplicación de las sanciones se utilizaba no sólo para castigar las supuestas "faltas" de las presas, sino también en función de las necesidades del servicio penitenciario, es decir, a veces las celadoras recibían la orden de sancionar sí o sí: "ahora nosotras estamos sancionadas hasta el 12 de enero sin visita a partir del 2. El parte dice como motivo cantar y bailar en las celdas refiriéndose al 31. Dentro de las cosas autorizadas para ese día estaban ampliar la lista de cosas para comprar en proveeduría, comer juntas, más horas de recreo interno, cantar, hacer teatro" (C. 41. 1979). La cita evidencia que, en esta oportunidad, las presas fueron sancionadas por realizar una actividad que previamente les había sido permitida. Con lo cual se interpreta que la sanción tuvo más que ver con las necesidades -o con el cinismo- del poder carcelario-militar.

Asimismo, la aplicación de las sanciones funcionaba de modo arbitrario, como se deja ver en esta cita que, ante una misma sanción impuesta colectivamente: “(...) después le levantaron [la sanción] a un grupo de compañeras y a otras no (...)" (C. 41. 1979). Del mismo modo, pareciera que la duración de la sanción se establecía no en función de la gravedad de la falta cometida, sino, nuevamente, en función de necesidades del penal: "De pronto las sanciones son largas, 15, 20 días, de pronto cortas, 5 días. En fin, todo es variable." (P. 51. 1979). A veces ocurría que estando las presas sancionadas alguien del servicio les comunicaba o la finalización anticipada de la sanción (por ejemplo, porque se habían ordenado traslados internos) o su extensión: "[la sanción] Dura hasta el 14 de julio inclusive y estamos en esta situación desde el 5 del corriente [junio]", y más adelante en la misma carta: "Recién nos acaban de comunicar que la sanción se prolonga hasta el 22 de julio." (S. 6. 1976). Es decir, se trata de una sanción que comenzó siendo de treinta y nueve días y terminó siendo de cuarenta y siete. Lo cual permite conjeturar que la duración de la sanción se determina en función de criterios que no son las supuestas faltas cometidas por las presas. Amén de la separación analítica en que se presentan aquí las formas de gobierno, se observa cómo en la práctica operaban de forma conjunta. En este caso, la sanción

\footnotetext{
${ }^{60}$ Borensztejn, Patricia, Hay que saberse alguna poesía de memoria, Buenos Aires, Capital Intelectual, 2011, p. 70

${ }^{61}$ Guglielmucci, op. cit. p. 97

${ }^{62}$ Gorini, Ulises y Oscar Castelnovo, Lilí presa política. Reportaje desde la cárcel, Buenos Aires, Antarca, 1986 , p. 56
} 
emerge en conjunción con el dispositivo de mantener a las presas bajo la incertidumbre acerca de su futuro inmediato (en este caso, la duración de la sanción).

No sólo la aplicación de las sanciones funcionaba de modo arbitrario, la misma discrecionalidad emerge además en las cartas en relación a algunas visitas: "Estoy escuchando los gritos de los niñitos que están en el patio y no me dejan concentrar, están ahí en el patio porque vinieron a la visita, resulta que, por el 25 de mayo, han dado visita de contacto solamente a algunas compañeras." (S. 56. s/f).

Por último, también era irregular la llegada de las encomiendas y los giros, los cuales eran esenciales para sobrellevar la vida diaria en el encierro, en la medida en que permitían sortear en parte la nocividad de las condiciones materiales de vida, puesto que recibían ropa, comida y objetos de uso diario y con los giros podían realizar ciertas compras en la "proveeduría" del penal.

\section{A modo de cierre}

A lo largo de este trabajo analizamos las formas que adquiere el gobierno carcelario cuando trata con una población específica en un contexto político particular: las presas políticas de la dictadura cívico-militar de 1976. Lo hicimos a partir de las cartas que ellas desde el encierro les enviaron a sus familiares, es decir, desde su propia experiencia y su propia voz.

Luego de presentar las características metodológicas con que se asumió el trabajo de interpretación empírica, presentamos la problemática de la prisión política en la última dictadura argentina. Se trata de una temática problematizada tardíamente en comparación con otras relativas al golpe de estado. Su incorporación en la agenda de las ciencias sociales, al asumir estrategias de análisis relacional, ha complejizado el conocimiento acerca del proceso dictatorial - por ejemplo, ha permitido pensar la articulación existente entre las cárceles "legales" y los centros clandestinos de detención.

En lo que refiere a la cárcel de Villa Devoto, a partir de las investigaciones previas sobre el tema, se reconstruyeron sus principales características. Fue una cárcel de máxima seguridad, donde se alojó a todas las presas políticas (a diferencia de los presos, que fueron distribuidos por diferentes cárceles en el interior del país). Su gobierno estuvo bajo mando conjunto del servicio penitenciario federal y del poder militar. Ubicada en un barrio de la capital federal, se erigió como "cárcel vidriera" donde el régimen visibilizó a las mujeres presas, en el marco de una estrategia de invisibilización de la política de secuestro, asesinato y desaparición de personas en los centros clandestinos de detención. Esta condición de "cárcel vidriera" fue utilizada al mismo tiempo por las presas políticas para ampliar sus grados de resistencia en relación al resto de los presos políticos.

En relación al tratamiento de la fuente empírica, a lo largo del análisis buscamos en las cartas aquellos indicios que nos permitieron reconstruir las formas concretas que asumió el gobierno carcelario en el marco de la política de aniquilamiento moral y político de las presas políticas. De este modo, describimos las formas de la disciplina impuestas sobre la vida y sobre los cuerpos de las presas políticas. Sus vidas diarias fueron normadas con una estricta disciplina horaria, sus cuerpos regulados en sus posturas e uniformados mediante la 
vestimenta. Por su parte, la producción del deterioro físico como forma de gobierno, se observó a partir de la descripción de las condiciones de infraestructura y alimentación degradantes a las que las presas políticas fueron sujetas.

Otros dispositivos de gobierno localizados fueron la "calesita" y las requisas. Mediante la "calesita", esto es, el traslado constante -y sin aviso previo- de celda y de pabellón, el régimen carcelario-militar perseguía el objetivo de impedir y coartar los lazos comunitarios y de afecto entre las presas. En cuanto a las requisas, al tiempo que quebraban el precario orden que las presas construían en sus vidas cotidianas, se erigían como los momentos donde el servicio penitenciario ejercía una de sus formas de poder más violenta sobre los cuerpos.

En cuanto a las sanciones "legales" como mecanismo de gobierno, se reconstruyeron tres tipos. El "plantón", que constaba en dejar a la presa política parada, con las manos en la espalda, durante horas; la "restricción", que implicaba la pérdida total o parcial de "beneficios", tales como recreos -internos y externos-, correspondencia, visitas, diarios y encomiendas; y el encierro en los calabozos de castigo, los "chanchos", celdas muy pequeñas, con pésimas condiciones de higiene, sin cama ni letrina, donde las presas quedaban totalmente incomunicadas durante días.

Finalmente, también señalamos el funcionamiento transversal de otro mecanismo de gobierno: la arbitrariedad. En este sentido se observó el caso de sanciones que se aplicaban a algunas presas y a otras no, sanciones que se levantaban antes de la fecha de finalización o se extendían por más días sin motivo aparente, entre otras.

Pero como señala Foucault ${ }^{63}$ en el ejercicio de poder la resistencia es una parte inherente. Por más que las fuerzas armadas se hayan concebido a sí mismas como totales, como señala Pilar Calveiro "Las líneas de fuga, los hoyos negros del poder son innumerables, en toda sociedad y circunstancia, aún en los totalitarismos más uniformemente establecidos". ${ }^{64}$ Las presas políticas resistieron la cárcel de múltiples maneras. A lo largo del trabajo hemos ido señalando algunas de las formas de resistencia desplegadas por las presas políticas en oposición a los dispositivos a que fueron sujetas. Esta línea de análisis cuenta con investigaciones rigurosas y exhaustivas ${ }^{65}$.

Para finalizar, no podemos dejar de señalar la existencia de continuidades entre las prácticas aquí estudiadas y el presente. La cárcel política y los centros clandestinos de detención inauguraron modalidades de represión que hoy parte de nuestro pueblo continúa sufriendo. Muchos de los dispositivos desplegados por los militares y por los servicios penitenciarios en las cárceles de la dictadura, fueron en su momento innovaciones en las formas de exterminio, dominación y opresión. Sin embargo, muchos de ellos siguen vigentes al día de hoy en las cárceles de la democracia ${ }^{66}$. El "enemigo interno" es otro y por eso mismo la estrategia represiva muta, sin embargo, son muchos los investigadores que hoy problematizan la temática de los derechos humanos en las cárceles, develando que se

\footnotetext{
${ }^{63}$ Foucault, Michel, Microfísica del poder, Madrid, Ediciones de La Piqueta, 1992.

${ }^{64}$ Calveiro, 2008, op.cit., p. 24, cursivas en el original.

${ }^{65}$ Ver D’Antonio, 2016, 2013, 2012 y 2011, op.cit. y Guglielmucci, op.cit. Además, para un análisis de las resistencias de las presas políticas realizado a partir de la fuente utilizada en este trabajo ver Laitano, 2017, op. cit.

${ }^{66}$ La continuidad entre la cárcel de la dictadura y las cárceles de la democracia es señalada en Garaño, op.cit., pp. 103-108.
} 
trata de derechos que son sistemáticamente violados por las condiciones de detención y por las torturas y vejámenes que se practican en los penales, donde los "chanchos" y las "calesitas" siguen constituyéndose en dispositivos útiles y disponibles para el gobierno de las cárceles.

\section{Bibliografía}

Águila, Gabriela, "La dictadura militar argentina: interpretaciones, problemas, debates", Páginas. Revista Digital de la Escuela de Historia, Rosario, Universidad Nacional de Rosario, año 1, $\mathrm{n}^{\circ}$ 1, 2008, pp. 11-27.

Beguán, Viviana (comp.), Nosotras, presas políticas, Buenos Aires, Nuestra América, 2006.

Borensztejn, Patricia, Hay que saberse alguna poesía de memoria, Buenos Aires, Capital Intelectual, 2011. Calveiro, Pilar, Poder y desaparición. Los campos de concentración en Argentina, Buenos Aires, Colihue, 2008.

Calveiro, Pilar, "Prólogo", Santiago Garaño y Werner Pertot, Detenidos-aparecidos. Presas y presos políticos de Trelew a la dictadura, Buenos Aires, Biblos, 2007, pp.15-20.

Castillo, Darcie Doll, "La carta privada como práctica discursiva. Algunos rasgos característicos", Revista Signos, 35 (51-52), 2002, pp. 33-57, disponible en: http://www.scielo.cl/scielo.php?pid=S071809342002005100003\&script=sci_arttext, (03/02/15).

D'Antonio, Débora, "Género y resistencias en la prisión política durante la última dictadura", Gabriela Águila, Santiago Garaño y Pablo Scatizza (coord.), Represión estatal y violencia paraestatal en la historia reciente argentina, La Plata, UNLP, 2016, pp. 186-206.

D'Antonio, Débora, "Reinterpretaciones, resistencias y negociaciones en la prisión política argentina 19741983", Outros Tempos, vol. 10, n 16, 2013, pp. 171-193.

D’Antonio, Débora, "Los presos políticos del penal de Rawson: un tratamiento para la desubjetivación Argentina (1970-1980)", Anos 90, Porto Alegre, v. 19, n. 35, 2012, p. 141-168.

D'Antonio, Débora, "Políticas de desarticulación de la subjetividad sexual y de género practicadas en la cárcel de Villa Devoto durante la última dictadura militar argentina (1976-1983)", Estudios, n 25, 2011, p. 159-174

D’Antonio, Débora y Ariel Eidelman, "El sistema penitenciario y los presos políticos durante la configuración de una nueva estrategia represiva del Estado argentino (1966-1976)", Nueva Época, año 10, n 40, diciembre 2010, pp. 93-111.

da Silva Catela, Ludmila, "De eso no se habla. Cuestiones metodológicas sobre los límites y el silencio en entrevistas a familiares de desaparecidos políticos", Historia, Antropología y Fuentes Orales, n² 24, 2000, pp. 69-75.

de Ípola, Emilio, La bemba. Acerca del rumor carcelario, Buenos Aires, Siglo XXI, 2005.

Foucault, Michel, Microfísica del poder, Madrid, Ediciones de La Piqueta, 1992.

Garaño, Santiago, Entre resistentes e "irrecuperables": Memorias de ex presas y presos políticos (1974-1983), Tesis de Licenciatura en Ciencias Antropológicas, Facultad de Filosofía y Letras, Universidad de Buenos Aires, 2008, disponible en http://www.antropojuridica.com.ar/wp-content/uploads/2012/03/GaranoTesis.pdf, $(22 / 04 / 15)$.

Ginzburg, Carlo, "El inquisidor como antropólogo", El hilo y las huellas. Lo verdadero, lo falso, lo ficticio, Buenos Aires, Fondo de Cultura Económica, 2011, pp. 395-411.

Ginzburg, Carlo, "Indicios. Raíces de un paradigma de inferencias indiciales", Mitos, emblemas, indicios. Morfología e historia, Barcelona, Gedisa, 2008, pp. 185-239.

Gorini, Ulises y Oscar Castelnovo, Lilí presa política. Reportaje desde la cárcel, Buenos Aires, Antarca, 1986. Guglielmucci, Ana, "Visibilidad e invisibilidad de la prisión política en Argentina: La 'cárcel vidriera' de Villa Devoto (1974-1983)", A Contra Corriente, vol. 4, n 3, 2007, pp. 86-136. 
Jensen, Silvina y María Montero, "La escritura epistolar como registro de la experiencia de encierro y represión en las cárceles argentinas (1974-1983)”, Historia Actual Online, n 31, primavera 2013, pp. 143-157, disponible en http://historia-actual.org/Publicaciones/index.php/haol/article/view/849/709 (07/03/17).

Laitano, Guillermina, "La comunidad de las presas políticas: la producción de lazos de cooperación y de afectividad como prácticas políticas de resistencia", Actas de las XVI Jornadas Interescuelas, 9 al 11 de agosto, 2017, Mar del Plata.

Laitano, Guillermina y Agustín Nieto, "El castigo como relación social cotidiana en la Argentina actual. El caso de la cárcel de mujeres de Batán", Revista Estudios Sociológicos, n 104, 2017, Colegio de México, pp. 293318.

Nieto, Agustín, "Los archivos policiales y la historia de las clases subalternas. El movimiento sindical marplatense a los ojos de la bonaerense", Los trabajadores del mar. Movimiento obrero en Mar del Plata (1957-1996), La plata, Comisión Provincial por la Memoria (ex-DIPPBA), 2011.

Pertot, Werner, "Palabras punibles. La ficción en la resistencia de los presos políticos", Iberoamérica, año 10, n 40, 2010, pp. 131-144.

Quiroga, Hugo, El tiempo del proceso. Conflictos y coincidencias entre políticos y militares, Rosario, Homo Sapiens, 2004.

Ruiz Olabuénaga, José Ignacio, Metodología de la investigación cualitativa, España, Universidad de Deusto, 2012.

Seveso, César, "Escuelas de militancia: la experiencia de los presos políticos en Argentina, 1955-1972", A Contra Corriente, vol. 6, $\mathrm{n}^{\circ}$ 3, primavera 2009, pp. 137-165. 